\title{
Aportes de la cartografía histórica para una historia ambiental en Misiones, Argentina (1880-1980)
}

\author{
Contributions of historical cartography for an environmental history in Misiones, \\ Argentina (1880-1980)
}

Contribuições da cartografia histórica para uma história ambiental em Misiones, Argentina $(1880-1980)$

\section{Resumen}

La cartografía histórica realiza un aporte fundamental a la historia ambiental, sobre todo porque permite estudiar cómo el medioambiente se fue creando en el tiempo. Este artículo nació para reflexionar sobre las características de la historia ambiental y cómo se pueden analizar los cambios y permanencias de un medioambiente a través de distintos mapas históricos. A fines expositivos se dividió el trabajo en tres grandes períodos, organizados por las características principales que definieron el proceso de poblamiento de la provincia de Misiones, Argentina, desde que se creó el Territorio Nacional (1881) hasta la última edición del "Gran Atlas de Misiones" (2013). El primer período (18811920) se caracteriza por la colonización

María Cecilia Gallero*

promovida por el estado y la ocupación espontánea; en tanto que el segundo por la iniciativa privada (1920-1953); y el tercero (1953-2013) por la consolidación y organización de una provincia.

Palabras clave: Historia ambiental. Cartografía histórica. Misiones, Argentina.

Ubicar acciones humanas en el espacio sigue siendo el mayor logro intelectual de los mapas como formas de conocimiento (HARLEY, 2005, p. 61).

\footnotetext{
" Doctora en Historia (Universidad Nacional de Cuyo). Investigadora Asistente en el Instituto de Investigaciones Humanas y Sociales, CONICET-UNaM, Argentina. E-mail: mariaceciliagallero@gmail.com

Recebido em 30/07/2015 - Aprovado em 17/03/2016 http://dx.doi.org/10.5335/hdtv.16n.1.6261
} 
Este artículo nació para reflexionar sobre el aporte heurístico de la cartografía para analizar la interrelación entre la naturaleza y la sociedad a través del tiempo y los cambios y permanencias en el medioambiente que se estudia, en este caso la provincia de Misiones, Argentina.

Los mapas replicados en este trabajo se han utilizado como "documentos" que permiten analizar que "la práctica cartográfica es un proceso de reterritorialización constante" (KITCHIN; DODGE, 2007, p. 335 apud LOIS, 2014, p. 35). En este sentido, la historia ambiental, como "saber ambiental" se proyecta "hacia el infinito de lo impensado -lo por pensar- reconstituyendo identidades en la reapropiación del mundo" (LEFF, 2009, p. 246). Un saber que busca descubrir la complejidad de la transformación del medioambiente de la provincia de Misiones, y que trata de comprender a través de diferentes mapas las huellas que dejó la "territorialización del estado" y descubrir cómo la cartografía fue mostrando la "intersección" entre la sociedad y la naturaleza. ${ }^{1}$

A fines expositivos se dividió el trabajo en tres grandes períodos, organizados por las características principales que definieron el proceso de poblamiento desde que se creó el Territorio Nacional (1881) hasta la última edición del "Gran Atlas de Misiones" (2013). El primer período (1881-1920) se caracteriza por la colonización promovida por el estado y la ocupación espontánea; el segundo por el poblamiento a partir de la iniciativa privada (1920-1953); y el tercero (1953-2013) por la consolidación y organización de una provincia.

La selección de la cartografía es el resultado de un largo proceso de búsqueda en el trabajo de campo de mi tesis doctoral ${ }^{2}$ (GALLERO, 2009). En este artículo no se ha podido replicar la misma en su totalidad o reproducir cartografía a color por razones de extensión y edición, sepa el lector disculpar este inconveniente, así también, como la omisión de las respectivas escalas o puntos de referencia, pues los mapas replicados en este trabajo se han utilizado como fuentes documentales que enlazan una narrativa coherente de imágenes sobre esta región.

\section{Delimitación y control nacional (1881-1920)}

Las formas de representar gráficamente el territorio crean el territorio mismo, adecuándolo a los intereses que impulsan el levantamiento de cada mapa (PRO RUIZ, 2011, p. 19).

En la segunda mitad del siglo XIX, durante el proceso de formación estatal, se llevaron a cabo diversas políticas orientadas a definir el territorio del Estado argentino. Luego de la Guerra de la Triple Alianza (1865-1970) el territorio de Misiones pasó a ser parte de Corrientes, provincia que había explotado sus riquezas naturales desde mediados del siglo XIX, como lo evidencia la creación de la "Jefatura Militar en Misiones para la Policía y protección de yerbales" (1856), institución que sentó los antecedentes de la actual Policía de la provincia. ${ }^{3}$

De esta época, la Carta Histórica de la provincia de Misiones de Martín de Moussy (1865), es un primer antecedente que muestra cómo se fue construyendo la imagen del espacio a integrar a la República (Figura 1). 
Este médico naturalista había sido contratado por Justo José Urquiza, presidente de la Confederación Argentina (1852-1861), para realizar una obra de carácter geográfico, en cuyo prefacio aclaraba "nuestro atlas es necesariamente aproximativo; pero tal como lo presentamos, dará así lo creemos, una idea bastante clara de la geografía de las provincias interiores" (MOUSSY, 2007, p. 25).

La intención era dar una "idea bastante clara de la geografía de las provincias interiores", un vasto territorio en el que no se marcan los límites políticos, ni estatales, ni provinciales. La superficie que comprende este mapa se extiende más allá del área que había sido ocupada por las Misiones Jesuíticas (1575-1768, según la propia leyenda de la Carta). El actual territorio provincial se encuentra ubicado exactamente en el centro de la carta, delimitado por los ríos limítrofes representados con su ancho algo exagerado, y destacados sus cursos mediante rayado. Miguel Ángel Stefañuk analiza que el trazado del río Paraná, presenta hasta la altura de Corpus cierta semejanza con la realidad, desde allí hacia el norte mantiene rumbo uniforme norte-noreste hasta la desembocadura del Iguazú ${ }^{4}$ (STEFAÑUK, 1995, p. 81).

Figura 1 - Carta Histórica de la provincia de Misiones (fragmento)

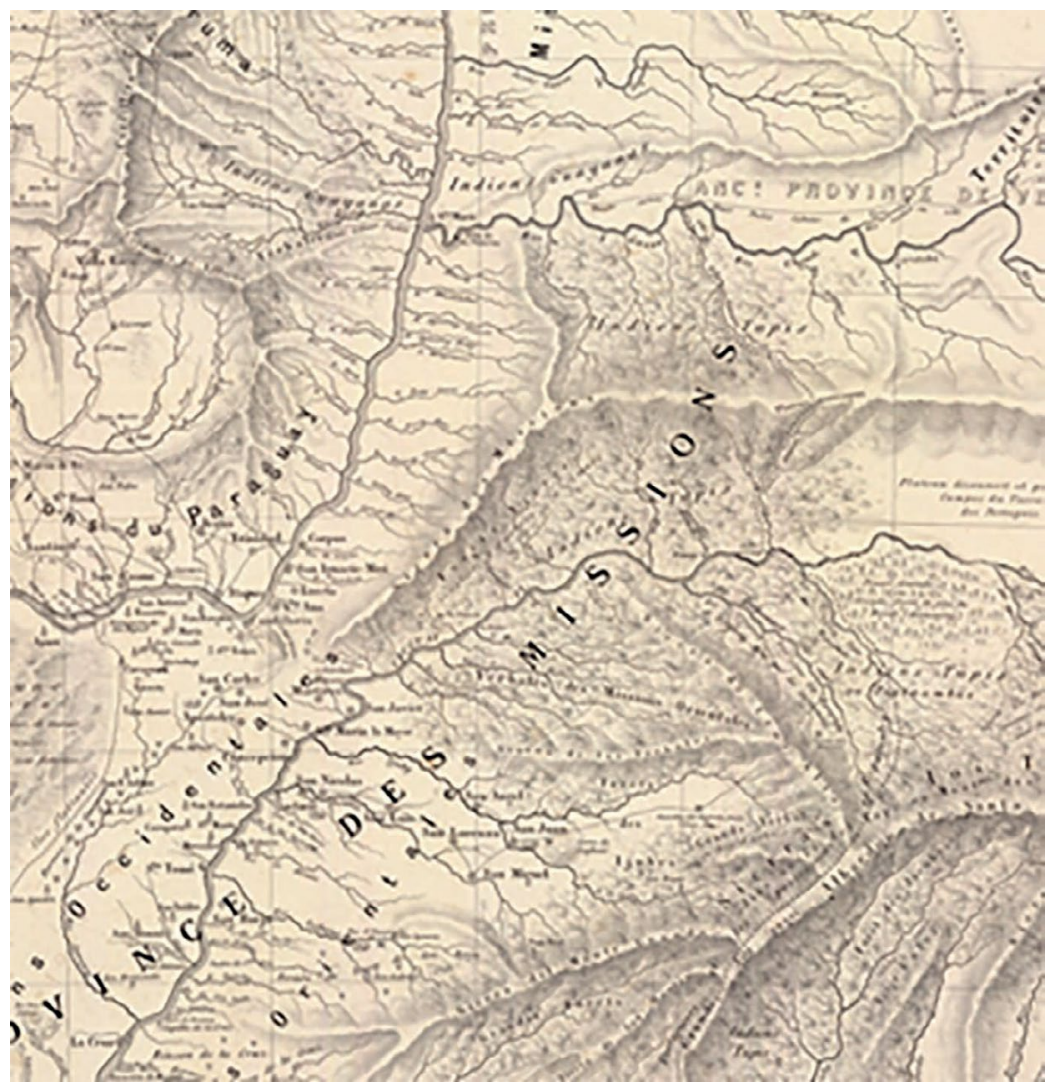

Fuente: Martín de Moussy, 1865 (MOUSSY, 2007). 
La mayor parte de este territorio estaba ocupado por la Selva Paranaense o Mata Atlántica, una selva subtropical húmeda con una gran biodiversidad que en el pasado cubría una enorme región de cien millones de hectáreas aproximadamente. Se extendía por la zona oriental del Paraguay, el sudeste de Brasil hasta la costa Atlántica y el estado de Sao Paulo al norte y la provincia de Misiones en Argentina. Esta selva se caracteriza por poseer una vegetación compacta, una alta densidad de ejemplares y una estratificación de pisos sucesivos de gran riqueza y extraordinaria variedad florística (BURKART et al., 2002).

Por otra parte, la creación de los territorios nacionales respondió a una búsqueda por definir la organización territorial ${ }^{5}$ - en su mayoría nacieron en la definición de los límites interprovinciales - y en el caso de Misiones su federalización generó una dura polémica entre la provincia de Corrientes y el gobierno nacional (1881). Para la dirigencia correntina, no había dudas respecto a sus derechos sobre el mismo. Sin embargo, cuando vieron que el proyecto igual se llevaría a cabo y que de ese modo perderían el usufructo de la tierra, la legislatura provincial autorizó la enajenación de los departamentos de Candelaria y San Javier, únicos existentes por entonces, limitados por la divisoria de aguas central, extendiéndose hasta el territorio litigioso perdido luego con Brasil. En esta venta, que se ha dado a conocer como "la noche triste de Misiones", se repartieron más de 762 leguas cuadradas entre 29 personas, una superficie equivalente a 2.101.936 ha del territorio misionero (las dos terceras partes de Misiones) (STEFAÑUK, 1999, p. 304).

En el mapa realizado por el Departamento Topográfico de Corrientes (Figura 2), se asignan las propiedades vendidas con un promedio de 70.000 ha por comprador. La exclusión de la franja central de Misiones sobre la divisoria de aguas en la repartición muestra el desconocimiento que había en la anchura del territorio entre los ríos Paraná y Uruguay. Otro ejemplo de esta situación es la diferencia en distancias entre los arroyos "pues para su confección se basaban en datos de los yerbateros y personas más o menos conocedoras de la región, que apreciaban a ojo las distancias, pero conocían perfectamente los nombres de los principales afluentes del Uruguay en sus barras" (STEFAÑUK, 1995, p. 98). 
Figura 2 - Croquis demostrativo de los terrenos de Misiones vendidos por el Gobierno la Provincia de Corrientes (1881)

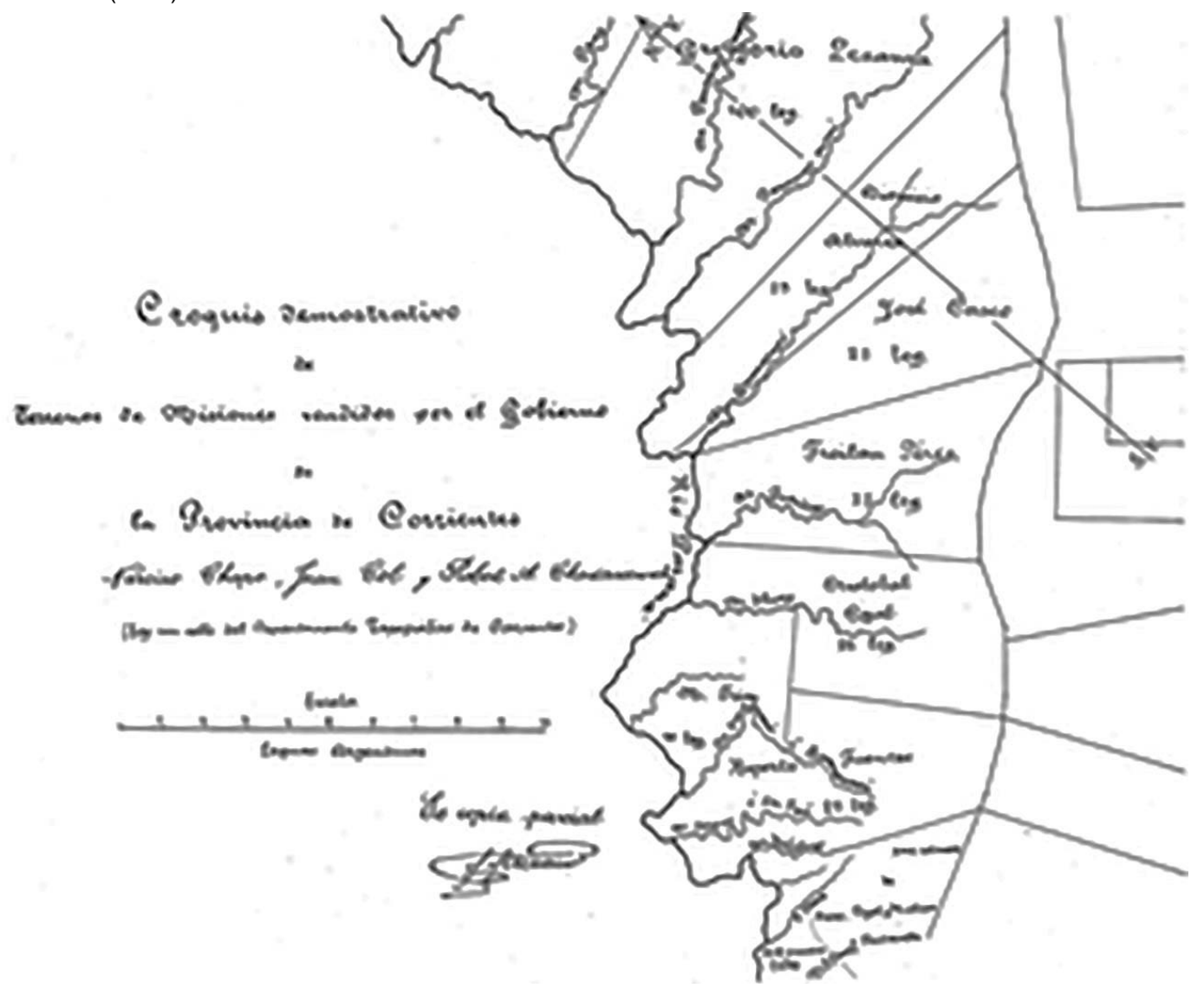

Fuente: Dirección General de Catastro de Misiones, Duplicado 58, reproducido por Dionisio Cáceres.

Ángela Perié de Schiavoni explica que "una imprecisa geografía daba cabida a una desmesurada ambición" (2006, p. 8-10). Como una brasa caliente, los predios pasaron de un comprador a otro. En muchos casos, fueron primero adquiridas por militares del regimiento comandado por Rudecindo Roca, pero rápidamente fueron transferidas. Finalmente, el gobierno nacional con la federalización obtuvo la jurisdicción política-administrativa del territorio, pero la propiedad de la tierra había quedado en su gran mayo- ría en manos privadas. Años más tarde, Faustino Berrondo Guiñazú, de la Dirección General de Tierras y Bosques de la Nación, realizó un meticuloso informe sobre este suceso y afirmó que fue un "procedimiento irregular que siguió el Gobierno de Corrientes en la enajenación de las tierras fiscales misioneras". ${ }^{6} \mathrm{Al}$ respecto de este gran negociado, Juan Queirel expresó "[estos] verdaderos latifundios que pesan y pesarán por mucho tiempo, como plomo sobre el progreso de Misiones" (QUEIREL, 1897, p. 365). 
En la Figura 3 se observa, que ante la ausencia de una cartografía precisa las propiedades vendidas varían en sus límites y que las ventas o transferencias se hicieron antes de ser mensuradas. De modo que el único ordenamiento que se mantuvo fue la adjudicación de las propiedades de Sur a Norte desde el arroyo Yabebiry hasta el arroyo Piray, y el límite Este (según el caso) fue la franja central de Misiones sobre la divisoria de aguas, el cual estuvo en litigio con el Estado Nacional hasta después de la provincialización del territorio.
En esta figura se observa cómo el agrimensor Lencisa intentó ponerle límite a las diez propiedades vendidas por Corrientes "...entre el río Paraná y la sierra de Misiones desde el arroyo Yabebiry hasta el arroyo Piray", y cómo por ejemplo, "no hay ubicación posible de la propiedad que fue de Antonio Rodriguez" (Aclaración de Lencisa en el mapa, Figura 3). Para evitar "conflictos graves con el fisco" nunca se llegaron a realizar "todos los deslindes", y fue así como el estado nacional fue legitimando la venta realizada por Corrientes.

Figura 3 - Mapa del Agrimensor Lencisa ubicando 10 propiedades de la venta (1881)

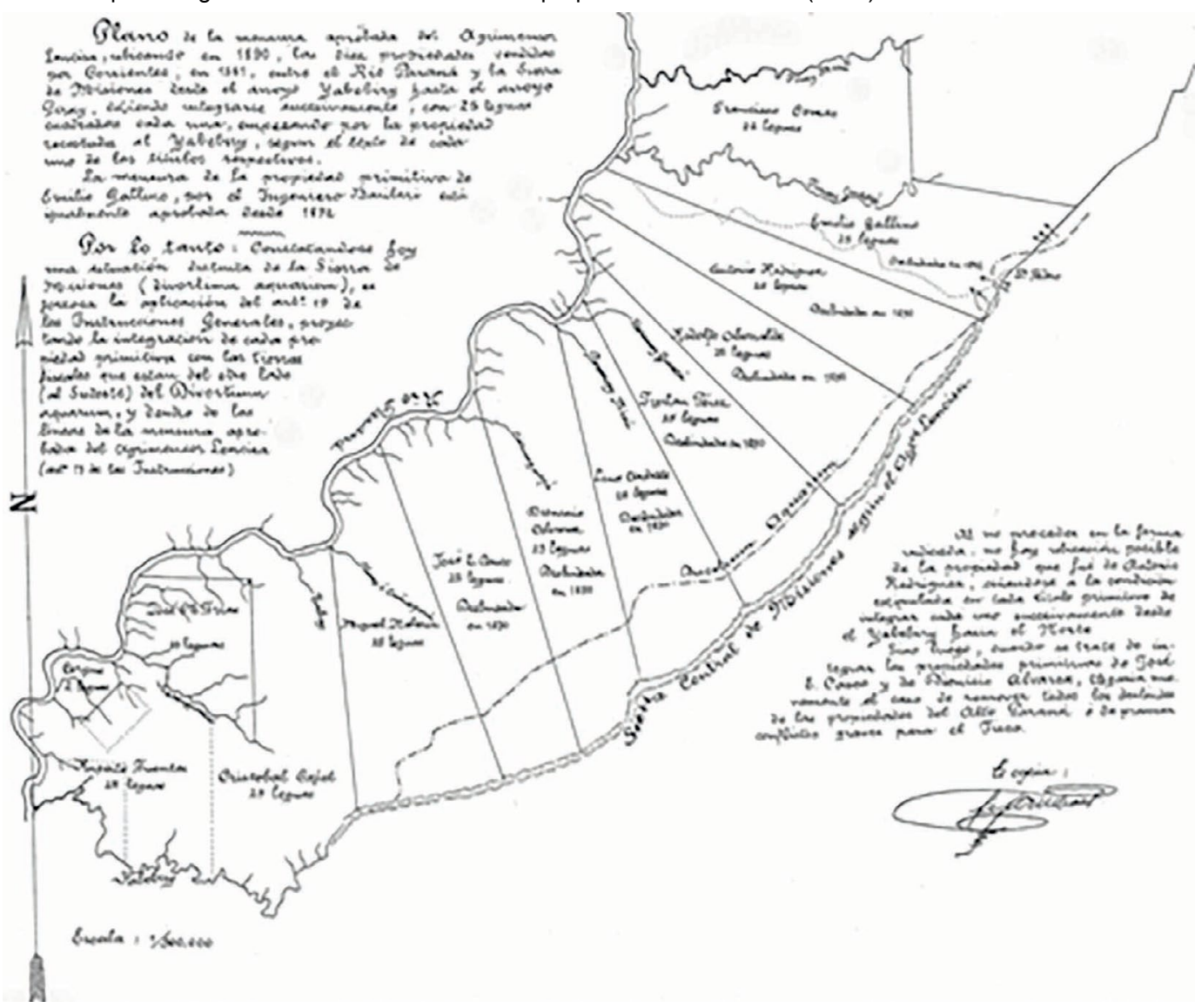

Fuente: Dirección General de Catastro de Misiones, Duplicado 78, reproducido por Dionisio Cáceres. 
En el mapa con la "Venta de Tierras Original" se pueden observar las propiedades particulares resultantes de dicha venta (Figura 4), mientras que en el mapa con la "Venta de tierras corregida" (Figura 5) se muestran cómo fueron reacomodadas luego de la pérdida del territorio correspondiente al Laudo Cleveland ${ }^{7}$ (1895).

\section{Figura 4 - Venta de tierras realizada por Corrientes}

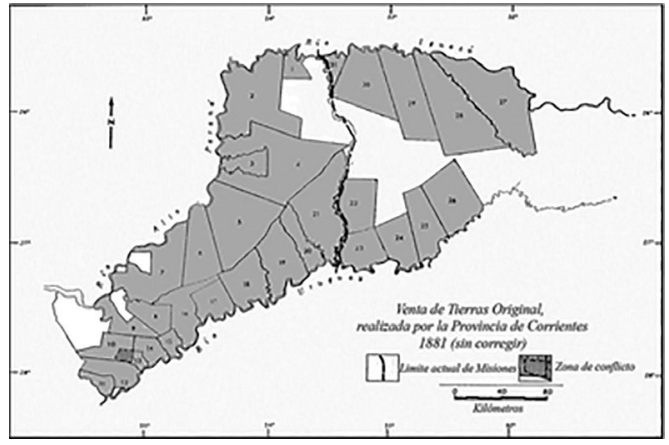

Fuente: Eidt (1971, p. 74).

Figura 5 - Venta de tierras corregida

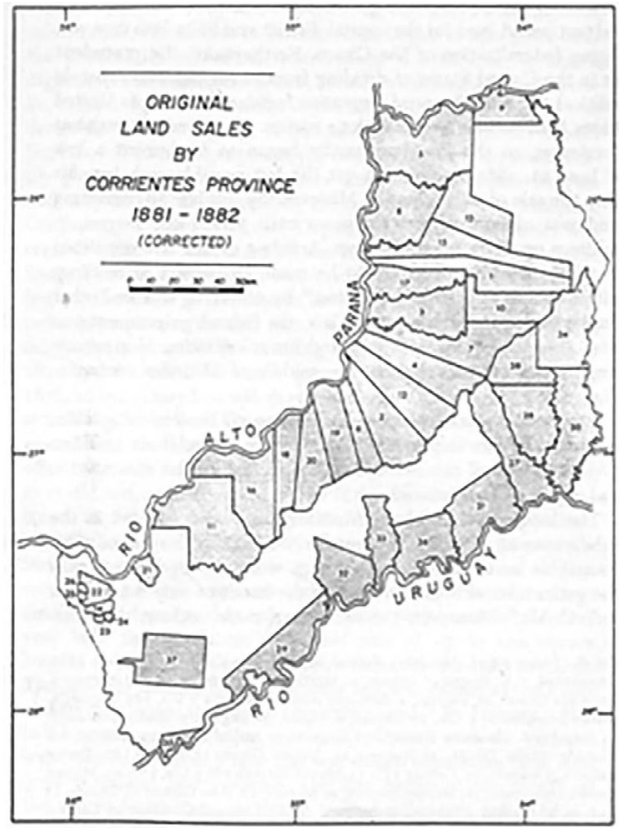

Fuente: Eidt (1971, p. 76).
Lo trascendente que se evidencia en este caso, y al cotejar con la bibliografía de la época, es que la ubicación de los principales arroyos que desembocan en el Río Paraná permaneció invariable. Sus nombres tardaron en definirse, por ejemplo, el actual arroyo Garuhapé, se lo encuentra denominado como "A. Caraguapepe", o "Guarapepe" ${ }^{\prime}$. Stefañuk precisa que este arroyo se encuentra citado en diversas obras cartográficas en una cantidad no inferior a diez denominaciones diferentes. El nombre definitivo "Garuhapé" llegó con el aporte del agrimensor Francisco Foulliand, pues precisamente en ese sector del río Paraná ubicado entre los arroyos Tabay, Cuñapirú y Garuhapé, el cambio de nombre de los mismos había dificultado la determinación de los arranques de mensuras de los predios vendidos por la Provincia de Corrientes. Al respecto Foulliand escribió:

[...] tanto tiempo como estuvo desierta o semi-desierta esta región boscosa de $\mathrm{Mi}$ siones pudieron existir discrepancias referentes a la denominación de los arroyos, pero hoy que los bosques están poblados y explotados intensivamente en toda la ribera del río Paraná, la denominación de los arroyos se ha fijado definitivamente [...] (STEFAÑUK, 2009, p. 290).

$Y$ se fueron fijando definitivamente para evitar litigios en la explotación de los bosques. En consecuencia, ante la falta de un conocimiento empírico de la topografía misionera el trazado de los límites de las mensuras se apoya en los ríos y arroyos "conocidos", sobre los que luego se fue imprimiendo la división político administrativa. 
En el "Mapa de Misiones" realizado por Foulliand en 1909 (Figura 6) se observa la división del territorio en las distintas propiedades que a su vez identifican al dueño de la misma, así también como los predios y colonias mensuradas hasta ese momento, varias de ellas por el mismo autor. Además, están marcados los pueblos, parajes, puertos y establecimientos, una hidrografía bien pergeñada y las vías de comunicación, tales como ferrocarril, caminos y picadas (STEFAÑUK, 1995, p. 134). Por ejemplo, en el territorio comprendido entre el arroyo 3 de Mayo y el Tabay, Foulliand grafica la picada yerbatera que va desde Paranay a un punto marcado como "Alves" y de allí a Tabay, citado por Gallardo como el "principal puerto para la extracción de la yerba elaborada en Campo Grande", y sobre el cual aclara que en sus proximidades "se elabora yerba de algunos manchones situados en el campo de propiedad del señor Errecabor$\mathrm{de}^{\mathrm{d}}$, en tanto que en el de "Caruapé" "también se embarca yerba y se forman angadas de madera [sic]" (GALLARDO, 1898, p. 225). Quince años más tarde, Niklison en su recorrido destaca el obraje de Pedro C. Labat en 3 de Mayo, del mismo Labat otro en Garuapé como "actualmente paralizado", en San Alberto cultivos que "no han prosperado", en Puerto León un obraje con "aserradero a vapor" y "buena organización", en tanto que en Tabay se encuentran tres puertos: Puerto Tabay Alvez y Puerto Tabay Arrechea con "trabajos en yerbales fiscales" y Tabay Damus con "obraje" (NIKLISON, 2009, p. 38).

La yerba mate que constituía uno de los recursos naturales más apreciados para fines del siglo XIX ya estaba mostrando síntomas de sobreexplotación: "duramente tratados por explotadores sin conciencia, que los han devastado, siguen dando hoy trabajo a varias empresas más o menos importantes" (GALLARDO, 1898, p. 19). Las "maderas de ley" fueron otro recurso que se explotaría durante todo el siglo XX. ${ }^{9}$ 
Figura 6 - Misiones, por Francisco Foulliand (1909)

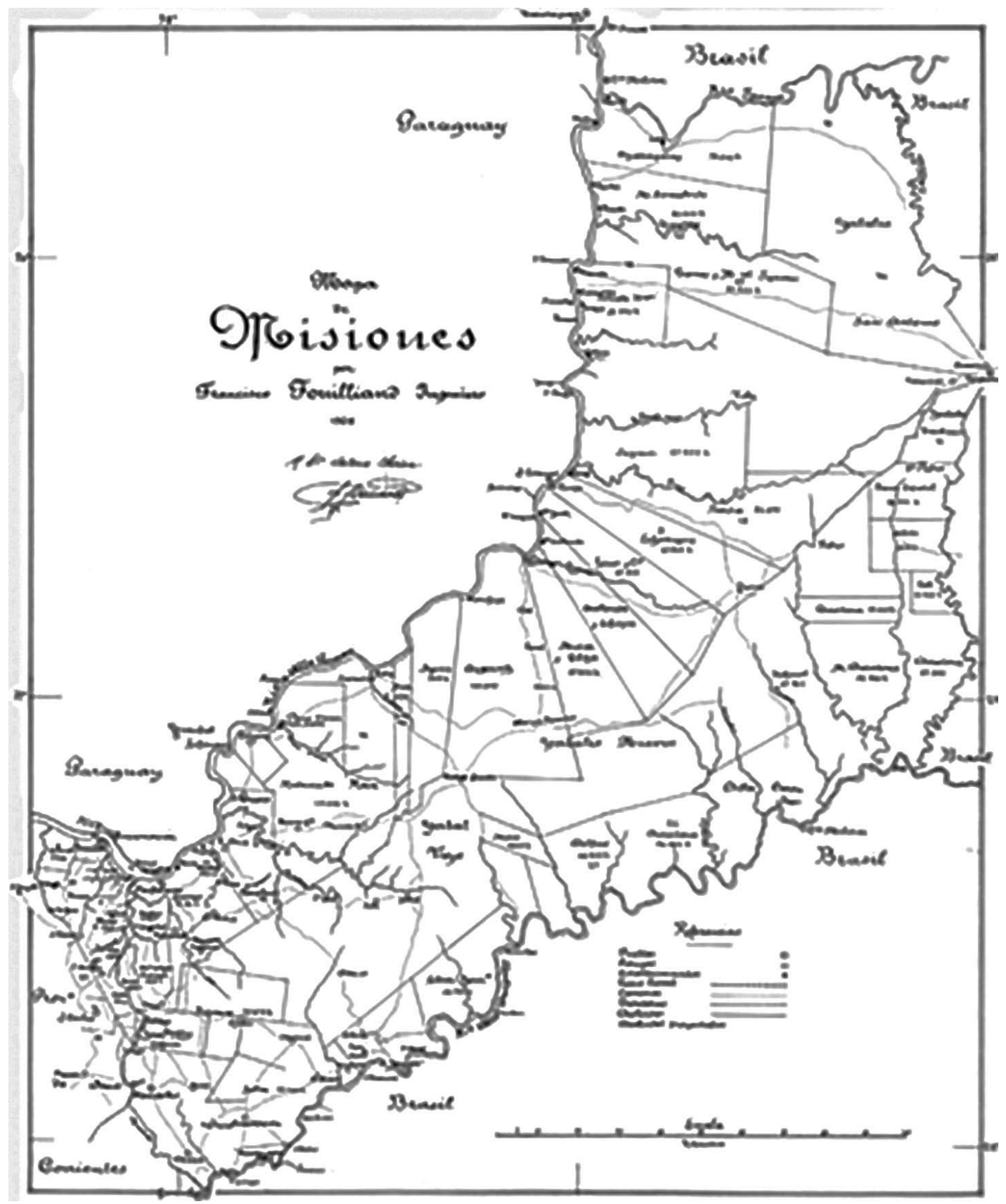

Fuente: gentileza Miguel A. Stefañuk. Reproducido por Dionisio Cáceres. 
En síntesis, en este período la colonización oficial se caracterizó por iniciarse refundando antiguos poblados jesuíticos, como Santa Ana y Candelaria (1883), más tarde con colonos polaco-ucranianos en Apóstoles (1898) y sus ensanches, San Ignacio (nuevo) (1907), o abriendo nuevos deslindes en el centro del territorio, como Aristóbulo del Valle (1921) o Leandro N. Alem (1926) (GALLERO, 2009, p. 38-42). La Dirección General de Tierras de la Nación era el organismo responsable del manejo de la tierra pública, asentado en el archivo de la División Geodesia, los antecedentes y diligencias de las mensuras, tanto de tierras fiscales como privadas.

La cartografía de este período refleja la apropiación de un territorio que se va estructurando a medida que se va conociendo y delimitando, en tanto que permite conocer los puntos de ingreso desde donde la economía extractiva explotaba los recursos y los lugares en los que la población empezaba a ser importante.

\section{0cupación y colonización efectiva}

$$
\text { (1920-1953) }
$$

Los mapas cartografían el poder que los produce, tanto o más que el espacio que dicen cartografiar (PRO RUIZ, 2011, p. 19).

En este período la ocupación se hizo efectiva a través de la colonización privada. El Alto Paraná había quedado vedado al accionar oficial y únicamente se pudo acceder al mismo cuando compañías privadas o particulares adquirieron la tierra y la destinaron a este fin. Las colonias de Puerto Rico y Montecarlo, junto a Eldorado se unificaron en un solo proyecto colonizador liderado por la Compañía Eldorado en 1924. Los accionistas desde temprano mostraron interés en que la colonización fuera un negocio redituable y en que estuviera dirigida hacia los inmigrantes de origen germano. No es causal entonces que estas colonias fueran vistas por mucho tiempo como asentamientos destinados a los colonos alemanes y sus descendientes (GALLERO, 2009, p. 105).

El mapa "Compilado y construido en la Gobernación de Misiones durante la administración del Dr. Héctor Barreyro, por el agrimensor nacional Don Adolfo Pomar" (Figura 7), realizado en escala 1:200.000,

[...] es un mapa catastral, donde se señalan las propiedades, se mencionan sus dueños, y los establecimientos, parajes, o puertos que se originaron a partir de su explotación y además los puertos paraguayos del Alto Paraná (STEFAÑUK, 1995, p. 144-147).

En muchos casos, los puertos coinciden con los que había visitado por Niklison en 1914, lo que muestra que el obraje y la economía extractiva marcaron el ingreso al territorio.

Stefañuk señala que en este mapa otro punto es que su extensión ha permitido el delineado del parcelamiento de las diversas colonias, sobre las que se destacan las de la zona sur, con la designación numérica de las chacras y dispuestos sus trazados en el clásico "damero" - nombre que deriva del tablero del juego de damas - o sea un fraccionamiento uniforme en lotes cuadrados, ajustados a las normas impuestas por el Ministerio de Agricultura de la Nación en Buenos Aires. ${ }^{10}$ 
Figura 7 - Mapa del Territorio de Misiones de Adolfo Pomar (c. 1920)

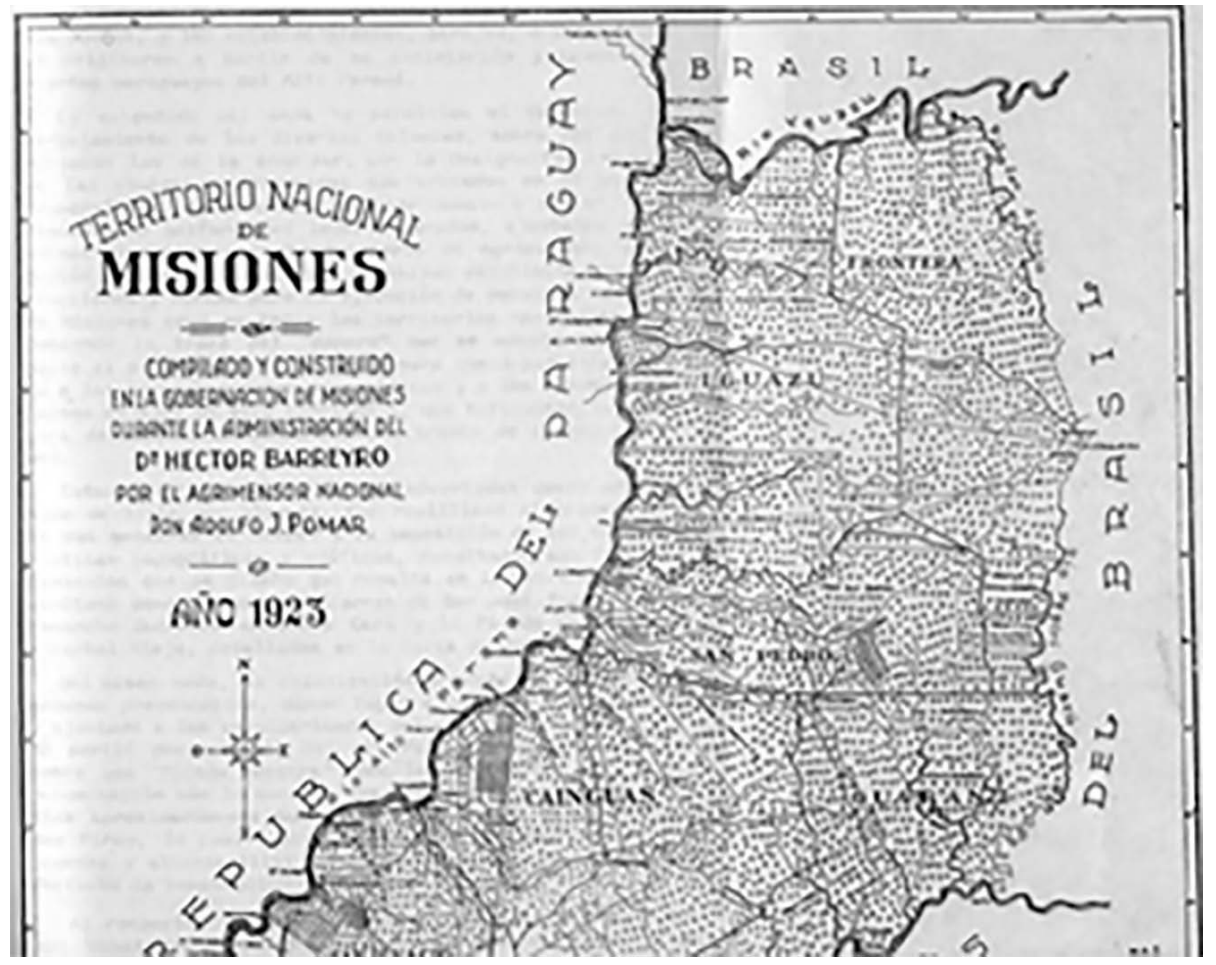

Fuente: Stefañuk (1995, p. 145).

El mapa que realizó Carlos A. Muello (1930), "Plano del Territorio de Misiones", sigue claramente el estilo marcado por Pomar, se observa una mayor precisión en destacar la colonización privada y los progresos que estaba realizando, o que restaban por realizar, en el que se especifica si era una "Colonia yerbatera", "Campos a colonizar", "Explotación yerbatera y ganadería" o un "Antiguo Obraje". En cambio, en el mapa editado por el anuario "Deutschen Kalender für den Alto Paraná" (Figura 8) - una clara reiteración del mapa de Muello adaptado para el lector germanoparlante -, se intenta marcar las incipientes colonizaciones, así como exhibir las hectáreas agrícolas en pro- ducción, como por ejemplo, de yerba 46.700 hectáreas con 45.622.00 plantas, Maíz 33.100 ha, Mandioca 5.400 ha, etc. (Cf. el epígrafe del mapa). En este anuario el acompañamiento cartográfico fue una característica, pues era una estrategia propagandística para mostrar el desarrollo del territorio y así incentivar la colonización. En este mapa, se nota la transformación que se estaba dando por el cambio de una economía extractiva a una productiva, como fuera analizado por Alfredo Bolsi al estudiar la relación entre el cultivo de la yerba mate y el poblamiento de Misiones (BOLSI, 1986).

Eric Tschumi en Tierra colorada dejó sentada una base descriptiva de los últimos 
años del Territorio Nacional, así por ejemplo, sobre la colonización privada afirma que fue un "aspecto fundamental del progreso" porque "hasta hace unos años integrantes de inmensos latifundios, que han sido librados al parcelamiento valorizador y a la construcción laboriosa del colono" (TSCHUMI, 1948, p. 231), y detalla los recientes emprendimientos que se estaban llevando a cabo, como Garuhapé, Jardín América, El Alcázar, Panambí, Alba Posse, Puerto Bemberg y Larrague; así como los desarrollados por la Compañía Colonizadora del Norte en Wanda y Lanusse, Monteagudo SRL en la colonia Ongay (actualmente El Soberbio).

Figura 8 - Karte von Misiones (fragmento)

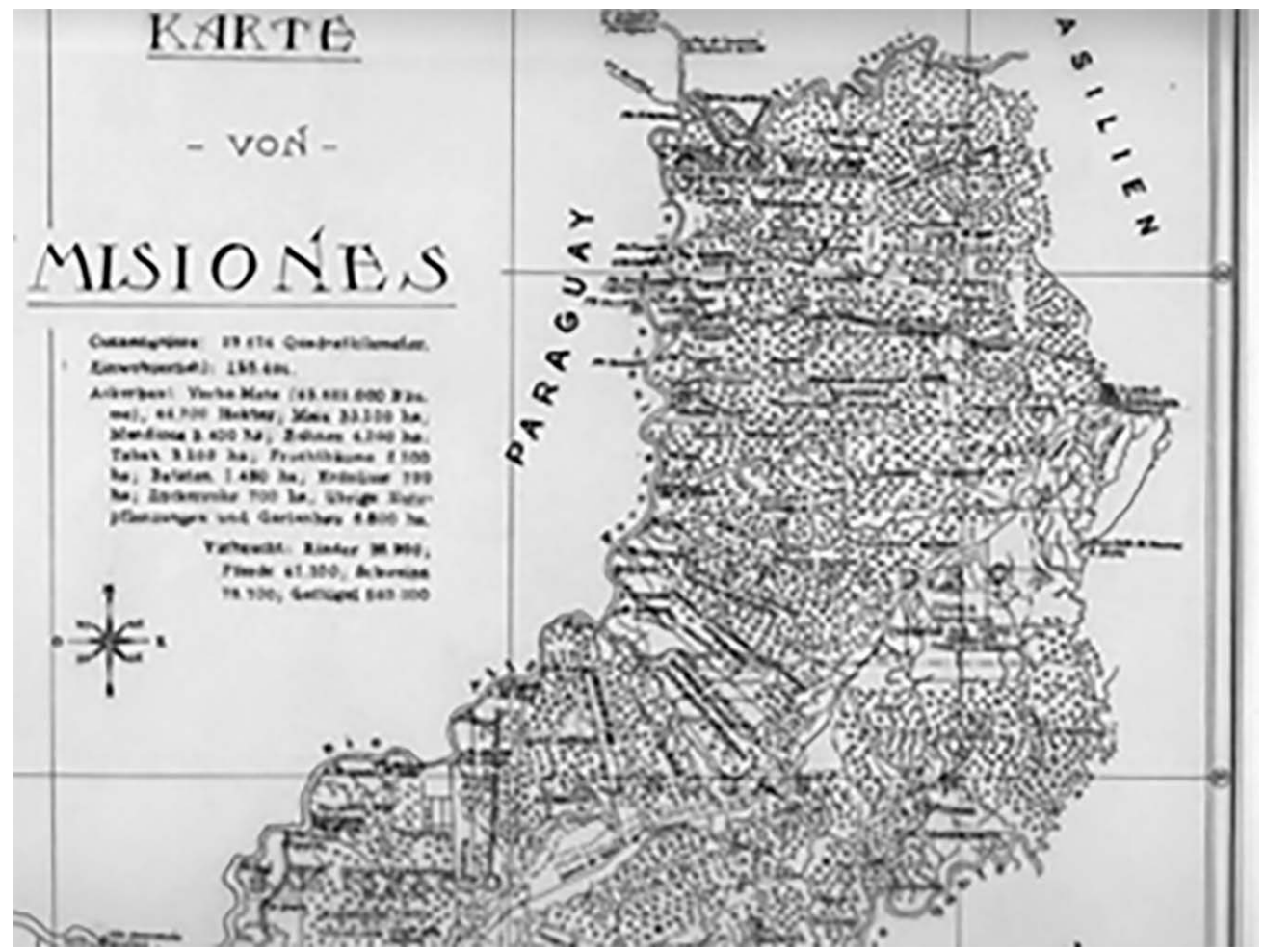

Fuente: Hassel, H. Karte von Misiones.

En el mapa analizado previamente se destacan los emprendimientos colonizadores, así como los propietarios privados que adquirieron la tierra. Aquí se hace eco la pregunta de Tim Ingold sobre la construcción del entorno y lo que significa decir que un entorno es construido. $\mathrm{Y}$ en este eco, la cartografía va mostrando cómo los seres humanos son autores de sus propios diseños, construyen a través de un proceso consciente de decisiones, en los que se pueden ver sucesivos escalones de "cooptación" y "construcción"11 (INGOLD, 2002, p. 175). 
El eco de este juego de cooptación y construcción se advierte en el modo en que la colonización privada pensaba cómo debía concretarse la colonización. En relación a la subdivisión y parcelamiento del terreno realizado por la "Compañía Colonizadora Alto Paraná" (1919-1924) hay que precisar que mientras en San Alberto se mantuvo el trazado en damero, en todos los otros lotes se implementó un trazado con características muy particulares: el sistema Waldhufendorf o Waldhufen [aldea o caserío con terrenos cultivables en el bosque o monte ${ }^{12}$ ] (EIDT, 1971, p. 122). Este sistema era adecuado para la ocupación de áreas boscosas con terrenos difíciles. La prioridad para la Compañía era activar la producción agrícola para darle vida a la colonia. La distribución de los colonos fue bastante homogénea: se asentaron pequeños grupos, alrededor de quince familias por cada fraccionamiento o Línea. Esto permitió un mayor contacto entre los pioneros, posibilitó que la colonización se fuera afianzando y contribuyó a generar un sentimiento de solidaridad grupal de larga duración en el tiempo.

Una idea rectora de la administración fue que todos los lotes tuvieran acceso al agua. En el folleto propagandístico de la compañía se aclara que la "hidrografía facilitó el trabajo de los ingenieros, a quienes les fue fácil prever en la demarcación para cada lote un curso de agua". Otro principio fundamental fue el de poseer "buenos caminos de tránsito [gute Verkehrsstrassen] para el desarrollo y el crecimiento de una colonia en el monte [Urwaldkolonie]". ${ }^{13}$ Por esta razón, se planificó que cada fracción estuviera atravesada por un camino principal [Autostrasse] y varios senderos paralelos a unos cuatrocien- tos metros de distancia, que unían cada lote con los centros urbanos y el puerto.

En la escritura de transferencia a la Compañía Eldorado se realiza una detallada descripción de los lotes que habían sido vendidos con anterioridad y que en ese momento se hallaban escriturados ${ }^{14}$ (Figura 9). En esta zona de nuevo asentamiento, la fuerza del Estado se hizo necesaria para garantizar las propiedades de nuevo cuño, midiéndolas con precisión, plasmándolas en planos, otorgándoles títulos oficiales, mensurado un territorio que es apropiado al mismo tiempo que va siendo delimitado.

Figura 9 - Lotes vendidos por la Compañía Colonizadora Alto Paraná (1925)

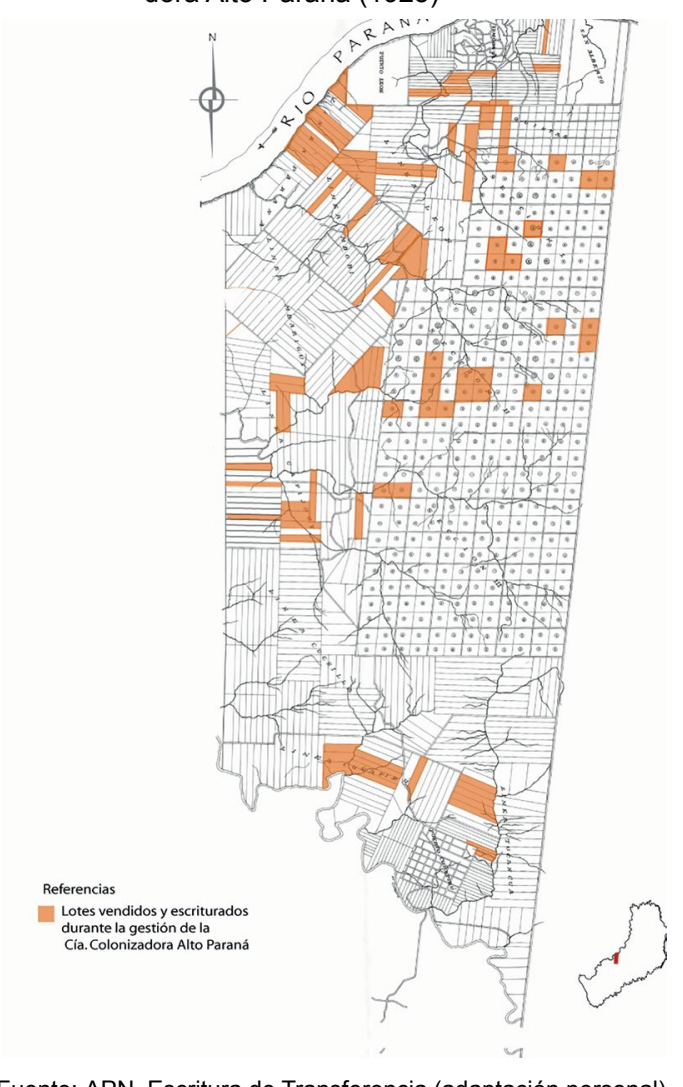

Fuente: APN, Escritura de Transferencia (adaptación personal). 
Del análisis realizado sobre este proceso de ocupación, se desprende que los lotes vendidos por la Compañía Colonizadora Alto Paraná (1919-1924) abrieron una frontera entre el espacio ocupado y la selva. Esta frontera poco a poco fue cediendo paso a la colonización, pero fueron esos primeros núcleos los que determinaron la tendencia de su desarrollo. En el análisis de la evolución del proceso de ocupación se destaca que el nexo de comunicación entre el puerto y el interior de la colonia fue la picada principal. Mientras la comunicación fue fluvial, la vida de la colonia se volcó hacia sus puertos, pero luego, paulatinamente fue suplantada por la comunicación terrestre, la que tuvo un impulso decisivo con la creación de la ruta nacional No 12 (c. 1939) (GALLERO, 2009).

Graciela De Marco afirma que el período de 1920-1947 marcó "la consolidación del afincamiento de la población" y que para el año 1947:

[...] se conocían 69 centros poblados de diferentes magnitud, entre ellos varios con menos de 100 habitantes. No existía un solo centro urbano que concentre más de 50.000 habitantes, existiendo solo tres que superaban los 2.000: Posadas con 37.000, Oberá con 4.823 y Apóstoles con 3.385 (DE MARCO, 1980, p. 239).

En la cartografía revisada ${ }^{15}$ se evidencia que la transformación de la selva paranaense comenzó a ser radical a partir del accionar colonizador de principios del siglo XX, de la expansión de la frontera agropecuaria y de la tala de bosques entre otras modificaciones antrópicas (GALINDO LEAL; GUSMÃO CÂMARA, 2005).

\section{De Territorio a Provincia (1953-2013)}

Los mapas redescriben el mundo, en términos de relaciones y prácticas de poder, preferencias y prioridades culturales (HARLEY, 2005, p. 61).

Para cuando el Territorio Nacional de Misiones se convirtió en Provincia (22-12 1953), la suerte estaba echada. Las tierras fiscales heredadas por la provincia estaban "cercadas" por las tierras privadas. El “Departamento de Geodesia y Topografía"16 se creó con la función de registrar y certificar el domino de la tierra tanto fiscal como privada (1957). En un primer momento se abrió un período denominado "toma de conocimiento" a fin de incorporar los planos de las mensuras, oficiales y privadas, con los que se elaboró un mapa catastral básico (1958), posteriormente rectificado por acciones de particulares a partir de información obtenida a través de una nueva documentación y particularmente con los resultados del relevamiento aerofotogramétrico realizado en el año $1960^{17}$ (PERIÉ DE SCHIAVONI, [1995?], p. 3).

Casi en paralelo a estos esfuerzos, se realizó una obra de carácter general Planeamiento de la Provincia de Misiones en la que se hizo la presentación formal de la provincia y se plantearon "los lineamientos a seguir en sucesivas responsabilidades en la conducción del Estado" (MISIONES, 1961). En esta obra uno de sus primeros mapas presenta el "paisaje natural" atravesado por las principales rutas y caminos, en los que se logran distinguir los principales arroyos misioneros y poblados. Paisaje natural y humano entrelazado que sienta las bases para mostrar el incipiente desarrollo de la provincia 
en el Atlas general de la provincia de Misiones (1978), una obra fundamental para el análisis de la metamorfosis medioambiental, que en su introducción plantea:

A partir de un espacio natural el hombre, agrupado en un conjunto social, va modelando su espacio vital: este espacio no es el fruto del azar ni un capricho de la naturaleza, sino la expresión física de un proceso socioeconómico que adapta el medio natural a los fines del desarrollo de una sociedad (MISIONES, 1978, p. 12).
Este atlas "es una colección ordenada de mapas" que utiliza el mapa por su "valor temático"18. En su segundo mapa (Figura 10) se ubica a Misiones en la región, la misma región que describiera y cartografiara Martín de Moussy, con la principal diferencia que los accidentes geográficos pasaron a un segundo planto ante las rutas y diferentes vías de comunicación.

Figura 10 - Misiones en la Región

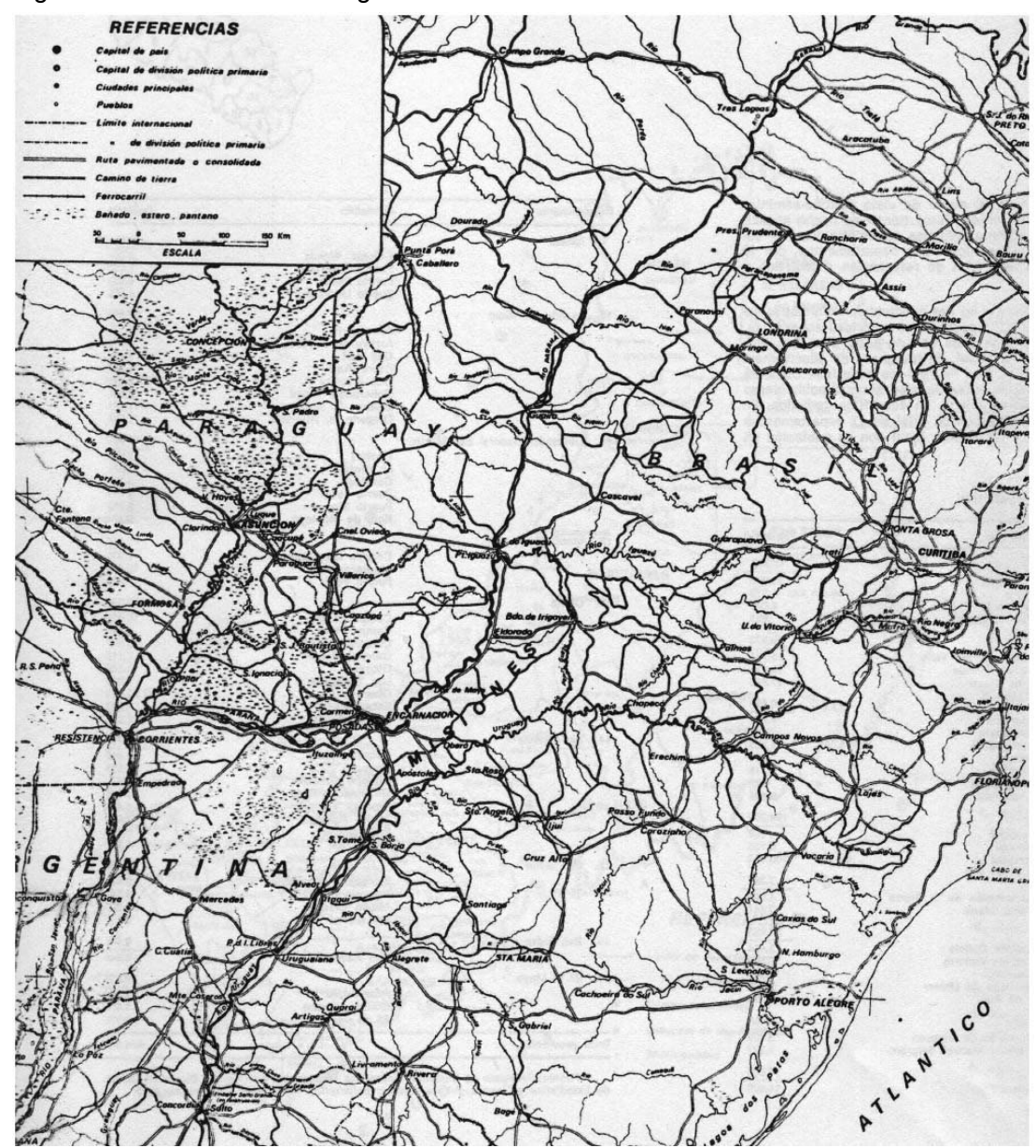

Fuente: Misiones (1978). 
Este Atlas finaliza con un intento de "zonificación" que intenta explicar en forma coherente la configuración espacial, que parte de ver que:

[...] la geografía de un lugar se va formando mediante la acción de un grupo social realiza sobre un espacio natural: la sociedad transforma, mediante la utilización económica y social de sus recursos, este espacio natural, le va dando una conformación afín a sus necesidades (MISIONES, 1978, p. 150).

En este punto hay que considerar que cada sociedad humana establece una relación particular con la naturaleza. El vínculo entre ambos tipos de sistemas (ecológicos y sociales) es la tecnología, como un conjunto de conocimientos y habilidades aplicados en la explotación de los recursos naturales, y en la interacción se determinarán "los patrones de ocupación del territorio y la forma de modificación del medio" (BRAILOVSKY; TIMM, 2014, p. 23).

Los patrones de ocupación - ya sea colonización oficial, privada o poblamiento espontáneo - impactaron en el medioambiente y realizaron modificaciones que se pueden estudiar y analizar. Uno de los más claros impactos - a nivel comparativo con los países vecinos - es el rastreo que se puede hacer en la cartografía para llegar a entender cómo Misiones concentró sus principales áreas boscosas en pocas y grandes propiedades, que le permitió crear el "Corredor Verde de la Provincia de Misiones", ${ }^{19}$ lo que se constituye en toda la eco-región de la Selva Paranaense:
[...] la última masa compacta con tamaño suficiente para que puedan subsistir en ella todas las especies de este riquísimo mundo silvestre, que es a su vez, el más rico en biodiversidad de la Argentina (BURKART et al., 2002, p. 13).

Más de tres décadas pasaron para que la provincia actualice la información en un "Gran Atlas de Misiones", ${ }^{20}$ el que más allá de ser un compendio de mapas geográficos en un solo volumen, es un libro

[...] que condensa información - en formato impreso y digital - acerca de lo que somos los misioneros en su compleja particularidad como sociedad joven, pujante e inserta como una cuña entre dos países con fuertes identidades nacionales (MISIONES, 2012, p. 3).

Dividido en siete partes, abarca respectivamente, información general, aspectos físicos y políticos, ecología, historia, turismo, economía, población, y departamentos y municipios. En la parte correspondiente a "ecología" se analiza la situación ambiental de la Selva Paranaense, utilizando cuatro mapas que la muestran en su extensión para los años 1900, 1940, 1970 y 2000 y evidencian el gran deterioro de la misma.

El Gran Atlas en su presentación se aclara que:

[...] es el resultado de una labor que se inscribe, precisamente, dentro de los órdenes de la sociedad del conocimiento, pues fue pensado, desde su origen, como un factor de desarrollo intelectual y cultural para usuarios de cualquier índole, atendiendo principalmente la urgencia de información actualizada que demandan los miles de estudiantes de nivel primario y secundario (MISIONES, 2012, p. 3). 
Ambos Atlas son una fuente cartobibliográfica importante para realizar una historia ambiental de la provincia. Sin embargo, interesa finalizar este apartado con el desafío que plantea Brian Harley para analizar el poder y la legitimación de los atlas. En su caso, Harley analizó cómo la estructura del poder social en una sociedad histórica particular influyó sobre la producción de conocimiento y su forma de representación en los atlas geográficos producidos en Inglaterra durante el siglo XVIII, será trabajo de futuras investigaciones realizar un estudio similar para los Atlas de Misiones. Sobre todo, intentar revisar el "poder externo y el poder interno en la cartografía” (HARLEY, 2005, p. 143).

\section{El aporte de la cartografía histórica a la historia ambiental}

[...] la cartografía es un arte de persuasión (HARLEY, 2005, p. 63).

La cartografía histórica realiza un aporte fundamental a la historia ambiental, sobre todo porque permite estudiar cómo el medioambiente se fue creando, no sólo perdiendo.

José Augusto Drummond (1991) da cuenta de las características metodológicas y analíticas para la historia ambiental en la lengua inglesa, los que se pueden ver replicados en todo análisis histórico cartográfico que se emprenda con miras en la historia ambiental. Estas características se pueden resumir en: 1) focalizar el análisis en una región con alguna homogeneidad o identidad natural, lo que evidencia la ligazón con la historia regional; 2) el diálogo sistemático con casi todas las ciencias naturales perti- nentes al entendimiento de los cuadros físicos y ecológicos de las regiones estudiadas; 3) explorar las interacciones entre el cuadro de recursos naturales útiles e inútiles a los diferentes estilos civilizatorios; 4) la gran variedad de fuentes pertinentes al estudio de las relaciones entre las sociedades y su ambiente, como el relato de exploradores, viajeros y naturalistas - en el caso aquí estudiado se agregan los mapas; y finalmente, 5) el trabajo de campo en el que la observación personal sobre el paisaje natural, clima, flora, fauna, ecología así como las marcas rurales y urbanas que la cultura humana deja en los paisajes (DRUMMOND, 1991, p. 181-185).

Las características mencionadas fueron tenidas en cuenta para la realización de este trabajo, y permiten dar cuenta de la importancia del marco metodológico al momento de llevar a cabo el análisis de la cartografía histórica. A través de los diversos mapas analizados se pudo reconstruir cómo la región se fue conformando y cómo la provincia de Misiones fue el resultado de la cooptación y construcción, en constante tensión entre las decisiones gubernamentales y el impulso de la sociedad, ya sea en sus esfuerzos a partir de la colonización privada o del poblamiento espontáneo.

La organización expositiva del trabajo en tres etapas permitió un juego paralelo en el cual el análisis metodológico fue puesto en práctica en un medioambiente particular: una ecorregión selvática con una gran diversidad que se encuentra críticamente amenazada. Región sobre la que se pasa de una visión en el que el medio natural se adapta a los fines del desarrollo (MISIONES, 1978) a una etapa que "reconoce el valor econó- 
mico de los servicios de la selva e integra la presencia del hombre con la conservación" (MISIONES, 2012).

Para finalizar este artículo, interesa plantear la conexión que se pueda establecer entre la cartografía histórica y "cartografía de la vegetación" como propone desarrollar interdisciplinariamente Gilbert Vargas Ulate de la Escuela de Geografía de la Universidad de Costa Rica. El interés de los trabajos cartográficos de las formaciones vegetales parte de utilizar la fotointerpretación, la cartografía digital y la teledección entre otros. Según este autor, la cartografía de la vegetación a pequeña y mediana escala se inició a partir de 1940 a causa del interés mostrado por las potencias coloniales europeas en los territorios africanos. La vegetación del pasado o histórica es la que ocupó un territorio en un momento determinado. La metodología que propone realiza dos tipos de análisis: el primero, de orden geográfico trata de la repartición y la delimitación espacial del fenómeno, mientras que segundo, es de orden ecológico y tiene como fin identificar y explicar el fenómeno natural, ambos muy difíciles de separar (VARGAS ULATE, 2012, p. 155). La cartografía de la vegetación es de gran importancia para el conocimiento de las formaciones y asociaciones a nivel de estructura, fisonomía y constitución florística, aunque su objetivo y utilización va a depender de la escala que se selecciona para hacer el mapa.

De este modo, la cartografía histórica se transforma en una herramienta indispensable para analizar los cambios que se han dado en el medioambiente, y es aquí que la historia ambiental sirve de apoyo a la educación ambiental - una educación que tiende a formar individuos que sepan reconocer la complejidad en la interacción entre lo "natural" y lo "social".

\section{Abstract}

The historical cartography makes a fundamental contribution to environmental history, especially because it allows to study how the environment has changed in time. This article was born to reflect on the characteristics of environmental history and how is possible to analyze changes and continuities of an environment through different historical maps. For expositive purposes this work is organized in three periods, each one by the main characteristics that defined the process of settlement of the province of Misiones, Argentina, since it was National Territory (1881) until the latest edition of "Great Atlas" (2013). The first period (1881-1920) is characterized by the colonization promoted by the state and the spontaneuous occupation; the second by private initiative (1920-1953); and the last one (1953-2013) by the consolidation and organization of the province.

Keywords: Environmental history. Historical cartography. Misiones, Argentina.

\section{Resumo}

A cartografia histórica traz um aporte fundamental para a história ambiental, sobretudo porque permite estudar como o meio ambiente foi sendo criado ao longo do tempo. Este artigo visa refletir sobre as características da história am- 
biental e como se pode analisar as mudanças e permanências de um meio ambiente por intrmédio de distintos mapas históricos. Dividiu-se o trabalho em três grandes períodos, organizados pelas características principais que definiram o proceso de povoamento da província de Misiones, na Argentina, desde que se criou o Território Nacional (1881) até a última edição do Gran Atlas de Misiones (2013). O primeiro período (1881-1920) caracterizou-se pela colonização promovida pelo Estado e a ocupação espontânea, o segundo se, pela iniciativa privada (1920-1953) e o terceiro (1953-2013), pela consolidação e organização de uma província.

Palavras-chave: História ambiental. Cartografia histórica. Misiones, Argentina.

\section{Notas}

1 Sergio Federovisky propone que la historia del medio ambiente, "en tanto intersección, empieza el día que se expresa el deterioro de la naturaleza por el impacto de la sociedad en su entorno" (2011, p. 25).

2 Dionisio Cáceres, Técnico Principal del Instituto de Investigaciones Geohistóricas (IIGHI-CONICET), realizó una minuciosa duplicación en papel vegetal de gran parte de esta cartografía.

3 Disponible en: <https://policiamisiones.gob.ar/ historiapolicia.pdf>. Consultada en: 10 marzo 2013.

4 En la descripción de este mapa Stefañuk agrega que el río Y-Guazú en su correcto arrumbamiento este-oeste, presenta dos inflexiones pronunciadas, una en el Salto de la Victoria (Cataratas del Iguazú) y otra al oeste del río San Antonio Miní (hoy San Antonio). Es evidente que este autor utilizó el material producido por los demarcadores, como lo demuestra el trazado del límite de las Misiones Orientales y la anexión de toponimia hidrográfica, constituida por afluentes del río Paraná que desde el Iguazú hacia el Sur son los siguientes: R. Mbucay (Mbocay), Mbarambas (Uruguay-1́), R. Agaray Guazú, R. Agaray Miní, R. Caraguapepé (¿), R. Piray Guazú, R. Piray Miní, (estos dos últimos en ese orden invertido), Parnay Guazú (Paranay Guazú),
Paranay Miní, R. Caraguapé (Garuhapé), Río de Corpus (probablemnte Curupaytí o el Oratorio o cazador, R. Yabebiry, Igarapa (Garupá). Las poblaciones indicadas son las once reducciones jesuíticas más la de San Carlos. Se ha representado con trazos de pendiente el relieve de las sierras del Imán y de Misiones, y también las áreas de selva virgen y ocupadas por árboles de yerba mate (STEFAÑUK, 1995, p. 81-82).

5 Entre 1872 y 1900 se crearon diez territorios nacionales, los que se se organizaron según lo dispuesto por la Ley Orgánica de los Territorios Nacionales 1.532 (1884).

6 Carta dirigida al interventor de la Dirección General de Tierras y Bosques, D. Amadeo Arrighi, 17/11/1947. en: Faustino R. Berrondo Guiñazú. Estudio sobre la 'Cuestión Misiones. 1ำ Parte. Mecanografiado, f. 8.

7 Las fracciones de este mapa corresponden a los siguientes compradores: 1. C. Boggio, 6 leguas; 2 . Martín Errecaborde y Cía, 100 leguas; 3. Francisco Comas, 25 leguas; 4 . Bernardo Acosta Chavarria y Cía, 125 leguas; 5. Martín Errecaborde y Cía, 73 leguas; 6. Gallán, 41 leguas; 7. Eladio Guesalaga, 25 leguas; 8. Desiderio Rossetti, 32 leguas; 9 . Andrés Rolán, 32 leguas; 10. Alaralde Adolvo Dávila, 27 leguas; 11. Justino Grané, 15 leguas; 12. Doctor Balestra, 3 leguas; 13. (?); 14. Martín Errecaborde y Cía, (?); 15. Manuel Cutchi, 25 leguas; 16. Manuel Herrera, 20 leguas; 17 . Rosa Cásares de Chaine, 15 leguas; 18. Santiago Regenal, 20 leguas; 19. Don Manuel Giménez, 25 leguas; 20. (?); 21. Olegario V. Andrade, 25 leguas; 22. Dolores Cásares, 25 leguas; 23. Antonio Cásares, 25 leguas; 24. Antonio Galarza, 25 leguas; 25. J. A. Cámpora, 25 leguas; 26. Olegario V. Andrade, 25 leguas; 27. Emanuel Montenegro, 25 leguas; 28. Pablo M. Yarsi, 25 leguas; 29. Francisco P. Rolón, 25 leguas; 30. Claudio Rolón, 25 leguas; 31. Picarello, 7 leguas (EIDT, 1971, p. 75).

8 En el "Mapa Gráfico de la Industria Yerbatera" de Carlos Gallardo de 1898, se puede ver marcado dicho puerto como "Caruapé" (GALLARDO, 1898).

9 La secuencia fue la siguiente: del bosque virgen se extraían Cedros, Lapachos, Inciensos y Peteribí, (las maderas denominadas "de ley") de buenos diámetros y buen fuste, ubicados sobre suelos más planos, luego en la segunda ya se agregó la madera para la industria del terciado: Guatambú, Guaicá, se bajó la exigencia para las maderas de ley y se comenzó la extracción de maderas duras de buena calidad como el Ibirá Pitá e Iberá Peré o Grapia, además, al mejorar la maquinaria se podía "entrar" en áreas que anteriormente estaban vedadas, luego en las intervenciones sucesivas se fue repasando todo, se agregó una categoría denominada "subproductos" para los diámetros menores de Cedro y Peteribí y se agregaron maderas para muebles como el Loro 
Blanco, duras como el Anchico y blandas como el Timbó, de esta manera la estructura florística de la selva misionera se fue degradando en forma continua a grandes pasos. Disponible en: < http://www. losquesevan.com/sobre-la-ley-de-ordenamiento-territorial-de-bosques-de-misiones.615c $>$. Consultado en: mayo 2013.

10 Este organismo establecía todas las instrucciones y normas para la ejecución de mensuras fiscales en Misiones como en todos los territorios nacionales, imponiendo el damero que se adapta perfectamente al parejo relieve de la llanura chaco-pampeana, pero no las irregularidades topográficas y a los innumerables cursos de agua de este territorio, que dificultan la apertura de caminos en línea recta a través de extensos tramos (STEFAÑUK, 1995, p. 147).

11 "In co-optive making an already existing object is fitted to a conceptual image of an intended future use, in the mind of a user. In constructive making this procedure is reversed, in that the objetc is physically remodelled to conform more closely to the pre-existing imagen" (INGOLD, 2002, p. 175).

12 Waldhufendorf: Wald: bosque; Hufen: porción de tierra cultivable generalmente entre 12 y 22 yugadas; Dorf: pueblo.

13 Compañía Colonizadora Alto Paraná. Folleto propagandístico. 1922. p. 4-8 (negrita en el original).

14 En total sumaban "en conjunto una superficie de 1556 ha. 28 a., que restados del área total que tenía el campo o sea en conjunto los lotes $1,2,3,4,5$ y 6 hacen que la superficie del inmueble Colonia Puerto Rico, formando por dichos lotes y que por este acto se enajena conste de 17899 ha. 26 a. 12 ca." En: APN, Escritura de Transferencia otorgada por la Sociedad Anónima Compañía Colonizadora Alto Paraná...Archivo de Protocolos Notariales, Colegio de Escribanos de la Ciudad de Buenos Aires. Escritura de Transferencia otorgada por la Sociedad Anónima Compañía Colonizadora Alto Paraná a favor de la Compañía Eldorado Colonización y Explotación de Bosques Limitada Sociedad Anónima, 7-11-1925, Escribanos Leopoldo Enrique Gutierrez y Jorge Ferrari, Registro 39, f. 107 v.

15 A la cual se suman las "Cartas Topográficas" del Instituto Geográfico Militar. Particularmente se han consultado: Hojas 2754-19 (Santo Pipó). Escala 1: 100.000, 1948; Hoja 2754-13 (Puerto Rico). Escala 1: 100.000, 1948; Hoja 2754-3, 2D4 (Puerto Rico). Escala 1: 10.000, 1962-1963; Hoja 2754-3, 4B1 (Oro Verde) Escala 1: 10.000, 1962-1963; Hoja 2754-3, 4B2 (Mbopicuá). Escala 1: 10.000, 1962-1963; Hoja 2754-3, 4B3 (Capioví). Escala 1: 10.000, 1962-1963; Hoja 2754-3, 4B4 (Capioviciño). Escala 1: 10.000, 1962-1963; Hoja 2754-3, 4D1 (Mineral). Escala 1: 10.000, 1962-1963; Hoja 2754-3, 4D2 (Capioví). Escala 1: 10.000, 1962-1963; Hoja 2754-3, 4D3 (Colonia Julio Martin). Escala 1: 10.000, 1962-1963;
Hoja 2754-3, 4D4 (Colonia Puerto Rico-Ruiz de Montoya). Escala 1: 10.000, 1962-1963.

16 En ese entonces dependiente de la Dirección General de Planeamiento, Arquitectura y Catastro del Ministerio de Economía y Obras Públicas. Actualmente depende del Ministerio de Hacienda y Economía y ha conservado su función: la de registrar y certificar todo lo referido a diseños y dominio de tierra tanto fiscal como privada.

17 La Ley 34: "Relevamiento aerofotogramétrico del territorio de la provincia" fue pensado para complementar con la "evaluación de sus recursos naturales por medio de la interpretación de las fotografías aéreas". Promulgada 2/9/1960 (MISIONES, 1965, Tomo I, p. 124-125).

18 La obra está dividida en ocho partes: la primera se refiere a la ubicación de Misiones, tanto en el contexto nacional como regional; la segunda a la descripción del medio natural; la tercera se dedica a la sociedad que modela su espacio; la cuarta a la educación y salud, la quinta y sexta parte se refiere a las actividades económicas; la séptima se dedica a la infraestructura y la última parte "es un intento de ordenar y agrupar los elementos del espacio misionero y de postular la existencia de áreas con características similares, o zonas, tendientes a posibilitar una comprensión lo más acabada posible de la geografía local" (MISIONES, 1978, p. 12).

19 Por la Ley 3.631, sancionada el 30/11/1999, se creó el "Corredor Verde" que consiste en áreas protegidas, propiedades privadas en usos diversos, colonias agrícolas, comunidades indígenas y variadas situaciones socioeconómicas, que tiene como fin garantizar a perpetuidad la conectividad de los tres principales bloques de Áreas Naturales protegidas de la selva paranaense en la provincia.

20 Gran Atlas de Misiones. Disponible en: < http:// www.ipecmisiones.com >. Acceso en: 26 agosto 2013.

\section{Referencias}

BERRONDO GUIÑAZÚ, Faustino. Estudio sobre la 'Cuestión Misiones', $1^{\circ}$ y $2^{\circ}$ Parte. Mimeo, 1947.

BOLSI, Alfredo. Misiones (una aproximación geográfica al problema de la yerba mate y sus efectos en la ocupación del espacio y el poblamiento). Folia Histórica del Nordeste, Resistencia: IIGHI-CONICET-FUNDANORD, n. 7, p. 9-253, 1986. 
BRAILOVSKY, Antonio; TIMM, Jésica. Economía y medio ambiente. Buenos Aires: Kraicon, 2014.

BURKART, R. et al. La Selva Misionera, Opciones para su conversación y su uso sustentable. Buenos Aires: FUCEMA, 2002.

DE MARCO, Graciela. El Nordeste Misionero: su poblamiento entre los años 1895 y 1970, Contribución a la geografía histórica de la Argentina. In: ENCUENTRO DE GEOHISTORIA REGIONAL, 1, 1980. Resistencia: IIGHI-CONICET, 1980. p. 213-261.

DIRECCIÓN GENERAL DE CATASTRO DE LA PROVINCIA DE MISIONES. Duplicados de Mensura: 20, 21, 58, 78, 90, 91, 103, 151 у 179. Posadas.

DRUMMOND, José Augusto. A história ambiental: temas, fontes e linhas de pesquisa. Estudios Históricos, Rio de Janeiro, v. 4, n. 8, p. 177-197, 1991.

EIDT, Robert. Pioneer settlement in Northeast Argentina. Madison: The University of Wisconsin, 1971.

FEDEROVISKY, Sergio. Historia del medio ambiente. Buenos Aires: Capital Intelectual, 2011.

GALINDO LEAL, Carlos; GUSMÃO CÂMARA, Ibsen de. Mata Atlântica: biodiversidade, ameaças e perspectivas. São Paulo: Fundação SOS Mata Atlântica; Belo Horizonte: Conservação Internacional, 2005.

GALLARDO, Carlos. La industria yerbatera en Misiones. Buenos Aires: Imprenta San Jorge, 1898.

GALLERO, María Cecilia. Con la patria a cuestas: la inmigración alemana-brasileña en la Colonia Puerto Rico, Misiones. Buenos Aires: Araucaria; Instituto de Investigaciones Geohistóricas, 2009.

HARLEY, J. B. La nueva naturaleza de los mapas: ensayos sobre la historia de la cartografía. México: Fondo de Cultura Económica, 2005.
INGOLD, Tim. The perception of the environment. London; New York: Routledge, 2002.

LEFF, Enrique. Racionalidad ambiental: la reapropiación social de la naturaleza. México: Siglo XXI, 2009.

LOIS, Carla. Mapas para la nación: episodios en la historia de la cartografía argentina. Buenos Aires: Biblos, 2014.

MISIONES. Atlas general de la Provincia de Misiones. Posadas: Secretaría de Planificación y Control, Dirección de Estadística y Censos, 1978.

Ley 34. Relevamiento aerofotogramétrico del territorio de la provincia. En: REPÚBLICA ARGENTINA. Leyes de la Provincia de Misiones. [S. 1.]: Honorable Cámara de Representantes, 1965. Tomo I. p. 124-125.

Gran atlas de Misiones. Posadas: Instituto Provincial de Estadística y Censos, 2012.

Planeamiento de la provincia de Misiones: Segunda parte: antecedentes y estudios regionales. Buenos Aires: Ministerio de Economía y Obras Públicas, 1961.

MOUSSY, Martín de. Martín de Moussy en la cuenca del Plata: su memoria histórica. Traducción de Roberto José Rolón. Buenos Aires: Los cuatro vientos, 2007.

MUELLO, Alberto Carlos. Plano del Territorio de Misiones. Escala 1. 400.000. 1930.

NIKLISON, José Elías. Vida y trabajo en el Alto Paraná en 1914. Documentos de Geohistoria Regional, Resistencia: IIGHI-CONICET, n. 16, 2009.

PERIÉ DE SCHIAVONI, Ángela. Indice Integrado. Archivo de Catastro de la Provincia de Misiones. [1995?]. Mimeo.

. Las tierras misioneras del Coronel Rudecindo Roca. Boletín de Junta de Estudios Históricos de Misiones, Posadas, p. 8-10, oct. 2006. 
PRO RUIZ, Juan. Introducción, mensuras, catastro y construcción estatal. In: GARAVAGLIA, Juan Carlos; GAUTREAU, Pierre (Ed.). Mensurar la tierra, controlar el territorio: América Latina, siglos XVIII-XIX. Rosario: Prohistoria Ediciones, 2011. p. 13-25.

QUEIREL, Juan. Misiones. Buenos Aires: Taller Tipográfico de la Penitenciaría Nacional, 1897. STEFAÑUK, Miguel Ángel. Diccionario geográfico toponímico de Misiones. Buenos Aires: Contratiempo, 2009.

Evolución de la cartografía de Misiones. Posadas: Montoya, 1995.

Patrón de asentamiento: su evolución histórica en la Provincia de Misiones. In: JORNADAS DE POBLAMIENTO, COLONIZACIÓN E INMIGRACIÓN EN MISIONES, 1, 1999. Posadas: Montoya, 1999. p. 301-310.

TSCHUMI, Eric. Tierra colorada. Buenos Aires: Talleres Gráficos Alemann y Cía, 1948.

VARGAS ULATE, Gilbert. La cartografía de la vegetación. In: BERGOEING GUIDA, Jean Pierre et al. La cartografía en la geografía. Costa Rica: Editorial Tecnológica de Costa Rica, 2012. p. 151-175. 